\title{
Do the Neutrophil/Lymphocyte Ratio and the Platelet/ Lymphocyte Ratio Have an Effect on Birthweight, Gestational Age and Severity of Prematurity?
}

\author{
Ayca Nazli Bulut ${ }^{*}$ (D) and Venhar Ceyhan, MD \\ Department of Obstetrics and Gynecology, Kayseri Training and Research Hospital, Kayseri, Turkey
}

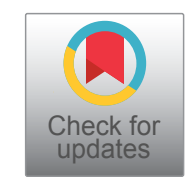

\author{
*Corresponding author: Ayca Nazli Bulut, MD, Department of Obstetrics and Gynecology, Kayseri Training \\ and Research Hospital, Kayseri, Turkey, Tel: +90-505-625-1433, Fax: +90-352-315-77-00
}

\begin{abstract}
Purpose: There are studies in literature which have reported that the neutrophile to lymphocyte ratio (NLR) is associated with gestational diabetes, pre-eclampsia, the severity of pre-eclampsia, premature prelabour rupture of membranes (PPROM) and hyperemesis gravidorum. There may also be an association with healthy pregnancies without any pathological conditions. The aim of this study was to investigate whether the neutrophil/lymphocyte ratio (NLR) and the platelet/lymphocyte ratio (PLR) have an effect on birthweight, gestational age and the severity of prematurity.

Methods: Data of 15000 women who delivered at the Kayseri Training and Research Hospital between May 2018 and December 2019 were retrospectively scanned. The complete blood count (CBC) values taken from the patients at least 1 month before the birth were used in the study. Primary outcome was to evaulate the effect of NLR and PLR on prematurity severity, birthweight and gestational week.
\end{abstract}

Results: A total of 637 patients who were randomly selected among the patients who met the criteria were included in the study. The gestational age at birth was determined to be associated with an increase in maternal $\mathrm{Hb}$ value and a decrease in PLR. A decrease in Hb, PLR, and neutrophil count, and an increase in BMI and NLR were each determined to be independent factors for birthweight.

Conclusion: This is the first study to have investigated the effect of PLR and NLR on the severity of prematurity. While no correlation was determined between the severity of prematurity and NLR, there was seen to be a weak positive correlation with PLR.

\section{Keywords}

Birthweight, Inflammation, Neutrophil/Lymphocyte ratio, Platelet/Lymphocyte ratio, Prematurity

\begin{abstract}
Abbreviations
AGA: Appropriate for Gestational Age; CBC: Complete Blood Count; CRP: C-Reactive Protein; IUGR: Intrauterine Growth Retardation; NLR: Neutrophile to Lymphocyte Ratio; PLR: Platelet/Lymphocyte Ratio; PPROM: Premature Prelabour Rupture of Membranes; SD: Standard Deviation; SGA: Small for Gestational Age; LGA: Large for Gestational Age
\end{abstract}

\section{Introduction}

Fetal growth is one of the signs of fetal health. Maternal inflammatory and thrombotic factors can affect the fetus through feto-placental-maternal circulation [1]. For the determination of fetal growth abnormalities, definitions of small for gestational age (SGA) and large for gestational age (LGA) are applied using weight percentiles according to the gestational week [2]. Premature birth is defined as birth $<37$ weeks and is associated with maternal inflammation [3].

SGA, LGA, and prematurity negative perinatal outcomes are closely related. Fetal growth may also be affected by ethnic and racial factors [4].

There are significant changes in the maternal hematological system throughout the process of pregnancy [5]. The most frequently seen hematological change is anemia $(\mathrm{Hb}<12 \mathrm{~g} / \mathrm{dL})$, the cause of which is increased plasma volume resulting in hemodilution [6]. Another variable is an increase in white blood cells. Leukocytosis develops because of physiological stress

Citation: Bulut AN, Ceyhan V (2022) Do the Neutrophil/Lymphocyte Ratio and the Platelet/Lymphocyte Ratio Have an Effect on Birthweight, Gestational Age and Severity of Prematurity?. Obstet Gynecol Cases Rev 9:219. doi.org/10.23937/2377-9004/1410219

Accepted: February 17, 2022: Published: February 19, 2022

Copyright: (C) 2022 Bulut AN, et al. This is an open-access article distributed under the terms of the Creative Commons Attribution License, which permits unrestricted use, distribution, and reproduction in any medium, provided the original author and source are credited. 
in pregnancy. Major leukocytes are neutrophils. While the leukocyte count decreases in the first and second trimester of pregnancy, it increases in the third trimester [7]. In platelet count, especially because of platelet aggregation occurring in the $8^{\text {th }}$ week of pregnancy, a significant decrease is seen from the $32^{\text {nd }}$ week onwards [6]. The role of these variables on fetal growth has still not been fully clarified.

There are studies in literature which have reported that the neutrophile to lymphocyte ratio (NLR) is associated with gestational diabetes, pre-eclampsia, the severity of pre-eclampsia, premature prelabour rupture of membranes (PPROM) and hyperemesis gravidorum [8-11]. In addition, the NLR and platelet to lymphocyte ratio (PLR) are known to be a sign of primarily various malignancies [12-16], several inflammatory processes like major cardiac events [17], cerebral hemorrhage [18], ischemic stroke [18], sepsis and infectious pathologies [19]. There may also be an association with healthy pregnancies without any pathological conditions [20,21].

Deviations in hematological variables may become significant problems in pregnancy and afterwards, but if variations in hematological parameters are known, these negative events can be minimalised from the beginning.

It was suggested that all these variables have an effect on infant birthweight and gestational age [22].

The aim of this study was to investigate whether the NLR, PLR and other CBC variabilites have an effect on birthweight, gestational age and the severity of prematurity.

\section{Material and Method}

The data of 15000 women who gave birth at Kayseri Research and Training Hospital between May 2018 and December 2019 were retrospectively scanned. The patients included in the study were those aged 18-40 years, women who give birth between $31^{+0}-41^{+}$weeks with a singleton pregnancy, with no systemic disease in the obstetric history, and who were not taking any vitamins, iron preparates or other medication for any reason. Patients with multiple pregnancies or any congenital anomalies were excluded from the study. Patients with high sedimentation, CRP, fibrinogen or procalcitonin, evidence of any infection, and a history of cervical insufficiency and premature birth at previous pregnancy were excluded from the study.

Approval for the study was granted by the Ethics Committee of Erciyes University. Informed consent for participation in the study was obtained from all the participants. (Ethical approval; Date: 29.01.2020. Referance number: 2020/53). All the study procedures were applied in compliance with the Helsinki Declaration.

The complete blood count (CBC) values taken from the patients at least 1 month before the birth were used in the study and the $\mathrm{CBC}$ values immediately before or after birth were not used. Blood collection time corresponded to the gestational week at least 4 weeks before the birth week. Therefore, the blood draw time of the patients who gave birth at different gestational weeks corresponded to different gestational weeks. A record was made for each patient of maternal age, weight and BMI, gravida, parity, a history and number of abortus, a history of cervical insufficiency and premature birth, infant gender and birthweight, and the FBC variables of $\mathrm{Hb}$, neutrophils, lymphocytes, NLR, platelets, PLR, PDW, RDW-sd, MPV, c-reactive protein (CRP), sedimentation, fibrinogen and procalcitonin values.

\section{Statistical Analysis}

Data obtained in the study were analysed statistically using SPSS vn. 25.0 software (SPSS Inc., Chicago, IL, USA). Continuous variables with normal distribution ( $p$ $>0.05$ in Kolmogorov-Smirnov test or Shapiro-Wilk [ $n<$ 30]), were reported as mean \pm standard deviation (SD) values, and those not showing normal distribution were stated as median values. Comparisons between groups were made using the Student's t-test or the One-way ANOVA test for normally distributed data, and the Mann Whitney U-test or Kruskal Wallis test were used for the data not normally distrubited. Since analysis of variance was significant, comparisons were applied using the Post Hoc test and the Mann Whitney U-test.

Categorical variables were analyzed between the groups using the Chi square test.Multiple linear regression analysis was applied to determineassociations between birthweight, gestational age at birth and other measurements, with birthweight or gestational age at birth as dependent variables. Correlations between variables were tested with Spearson's correlation coefficient. Correlation coefficients were interpreted as either an excellent relationship $r \geq 0.91$; good $0.90 \geq r \geq$ 0.71 ; fair $0.70 \geq r \geq 0.51$; weak $0.50 \geq r \geq 0.31$; little or none $r \leq 0.3$.

\section{Results}

According to the sample calculation, 637 people who met the criteria with $95 \% \mathrm{Cl}$ and $90 \%$ power were randomly selected and included in the study [22]. G-Power 3.1 program was used for sample calculation. The 637 patients were separated into groups according to birthweight and gestational age at birth. Those who gave birth at $<37$ weeks were accepted as the preterm group, which was divided into 3 subgroups of $31^{+0}-32^{+6}$ weeks, $33^{+0}-34^{+6}$ weeks, and $35^{+0}-36^{+6}$ weeks. Birthweight according to gestational age at birth was accepted as SGA $<10$ th percentile [23], AGA $10^{\text {th }}-90^{\text {th }}$ percentile, and LGA $>90^{\text {th }}$ percentile [24].

\section{Demographic Data}

Birth was preterm in $21.7 \%$ ( $n: 138)$ of the patients 
Table 1: Demographics of the patients.

\begin{tabular}{|c|c|}
\hline Demographics & Values $(n=637)$ \\
\hline Age (year) (mean \pm sd) & $26.5 \pm 5.9$ \\
\hline BMI $\left(\mathrm{kg} / \mathrm{m}^{2}\right)($ mean $\pm \mathrm{sd})$ & $28.6 \pm 4.9$ \\
\hline Graida [median (min-max) & $3(1-11)$ \\
\hline Parity [median (min-max) & $2(1-8)$ \\
\hline Smokingstatus [n, (\%)] & $76(11.9)$ \\
\hline \multicolumn{2}{|c|}{ Fetal growth status according to gestational age [n, (\%)] } \\
\hline SGA & $198(31.1)$ \\
\hline AGA & $242(38)$ \\
\hline LGA & $197(30.9)$ \\
\hline Preterm Labour [n, (\%)] & $138(21.7)$ \\
\hline $31^{+0}-32^{+6}$ & $16 / 138(11.6)$ \\
\hline $33^{+0}-34^{+6}$ & $33 / 138(24)$ \\
\hline $35^{+0}-36^{+6}$ & $89 / 138(64.4)$ \\
\hline Gestational week at labour (week) (mean \pm sd) & $37.9 \pm 2.1$ \\
\hline Birthweight (gram) (mean \pm sd) & $2974.4 \pm 757.4$ \\
\hline \multicolumn{2}{|l|}{ Fetalgender [n, (\%)] } \\
\hline Female & $304(47.7)$ \\
\hline Male & $333(52.3)$ \\
\hline \multicolumn{2}{|l|}{ Laboratory data (mean $\pm \mathrm{sd}$ ) } \\
\hline $\mathrm{Hb}(\mathrm{gr} / \mathrm{dL})$ & $12.1 \pm 1.3$ \\
\hline Wbc $\left(X 10^{9} / L\right)$ & $10.8 \pm 3.9$ \\
\hline Platelet (X103/L) & $241178.9 \pm 63333.1$ \\
\hline 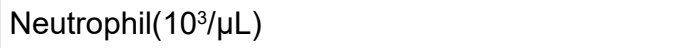 & $10.3 \pm 5.76$ \\
\hline Lymphocyte $\left(10^{3} / \mu / L\right)$ & $2.5 \pm 0.56$ \\
\hline PDW (\%) & $12.3 \pm 2.6$ \\
\hline MPV (fL) & $10.4 \pm 1.1$ \\
\hline RDW (\%) & $14.3 \pm 2.4$ \\
\hline $\mathrm{N} / \mathrm{L}$ ratio & $4.1 \pm 2.2$ \\
\hline $\mathrm{P} / \mathrm{L}$ ratio & $25608.4 \pm 10808.7$ \\
\hline
\end{tabular}

BMI: Body Mass Index; SGA: Small for Gestational Age; AGA: Appropriate for Gestational Age; LGA: Large for Gestational Age; Hb: Hemoglobin; Wbc: White Blood Cell; PDW: Platelet Distribution Width; RDW: Red Cell Distribution Width; MPV: Mean Platelet Volume; N/L: Neutrophil to Lymphocyte Ratio; P/L: Platelet to Lymphocyte Ratio

Table 2: Comparative data of groups formed based on infant weight according to gestational age.

\begin{tabular}{|c|c|c|c|c|}
\hline & AGA $(n=242)$ & $\operatorname{LGA}(n=197)$ & IUGR $(n=198)$ & $\mathbf{p}$ \\
\hline Age (year) (mean \pm sd) & $26.7 \pm 6.0$ & $27.1 \pm 6.1$ & $26.3 \pm 5.6$ & 0.137 \\
\hline Height $(\mathrm{cm})($ mean $\pm \mathrm{sd})$ & $162.1 \pm 20.8$ & $164.1 \pm 21.9$ & $159.9 \pm 5.4$ & 0.259 \\
\hline Weight $(\mathrm{kg})($ mean $\pm \mathrm{sd})$ & $73.4 \pm 12.8$ & $80.4 \pm 14.5$ & $69.7 \pm 11.7$ & 0.0001 \\
\hline $\operatorname{BMI}\left(\mathrm{kg} / \mathrm{m}^{2}\right)($ mean $\pm \mathrm{sd})$ & $28.3 \pm 5.0$ & $30.2 \pm 5.3$ & $27.2 \pm 4.1$ & 0.0001 \\
\hline Gravida [median (min-max)] & $3(1-9)$ & $3(1-11)$ & $2(1-7)$ & 0.001 \\
\hline Parity [median (min-max)] & $2(1-8)$ & $3(1-8)$ & $2(1-6)$ & 0.001 \\
\hline Abortion [median (min-max)] & $0(0-3)$ & $0(0-4)$ & $0(0-3)$ & 0.988 \\
\hline Smoking status ([n, (\%)] & $25(10.3)$ & $12(6.09)$ & $42(21.2)$ & 0.001 \\
\hline
\end{tabular}

BMI: Body Mass Index; AGA: Appropriate for Gestational Age; LGA: Large for Gestational Age; SGA: Small for Gestational Age. $P<0.05$; Statisticaly Significant. 
and term in $78.3 \%$ ( $\mathrm{n}: 499)$. The demographic data of the patients are shown in Table 1.

\section{Data of the Group Comparisons}

The comparative demographic data of the groups showing different growth patterns according to the gestational age are shown in Table 2.

When the LGA group and the other groups were compared, no difference was observed in the N/L ratio and $P / L$ ratio. When the $S G A$ group and other groups were compared, there was no difference in the $\mathrm{N} / \mathrm{L}$ ratio and $\mathrm{P} / \mathrm{L}$ ratio. In SGA grpoup, the $\mathrm{Hb}$ value was observed to be statistically significantly higher than that of the

Table 3: Correlations among the variables.

\begin{tabular}{|l|l|l|l|}
\hline & & Birth Week & Birth Weight \\
\hline Age & r & 0.04 & 0.09 \\
\hline Hb & r & $0.14^{*}$ & -0.07 \\
\hline Neutrophil & r & -0.06 & -0.03 \\
\hline Lymphocyte & r & 0.04 & 0.03 \\
\hline WBC & r & -0.06 & -0.08 \\
\hline Platelets & $r$ & -0.02 & -0.07 \\
\hline PDW & $r$ & 0.07 & -0.01 \\
\hline RDW & $r$ & 0.01 & $0.12^{*}$ \\
\hline MPV & r & 0.07 & -0.02 \\
\hline N/L Ratio & r & -0.05 & -0.04 \\
\hline P/L Ratio & $r$ & $-0.09^{*}$ & $-0.09^{*}$ \\
\hline
\end{tabular}

N/L: Neutrophil to Lymphocyte Ratio, P/L: Platelets to Lymphocyte Ratio; $r=$ Correlation Coefficients; * $P<0.05$ other groups ( $p=0.0001$ ). A statistically significantly higher rate of female infants was seen in the SGA group $(p=0.007)$, and of male infants in the LGA group ( $p=$ 0.007 ). Infant gender was not seen to have any effect on the hematological parameters.

The rate of SGA infants in this Turkish population was statistically significantly higher than in other ethnic groups $(p=0.001)$.

\section{Comparison of the Laboratory Test Results}

A statistically significant difference was determined only in the $\mathrm{Hb}$ value, with the highest value determined in the SGA group $(p=0.025)$. No other statistically significant difference was observed between the groups in respect of the other laboratory results. The lowest NLR was observed in the SGA group. The highest PLR was observed in the SGA group and the lowest PLR in the LGA group.

When maternal age and $C B C$ variables were evaluated sepatrately, no statistically signficant effect was determined on birthweight or gestational age at birth (Table 3). In the multivariate linear regression analysis, gestational age at birth was determined to be associated with an increase in maternal $\mathrm{Hb}$ value and a decrease in PLR (Table 4) while a decrease in Hb, PLR, and neutrophil count, and an increase in BMI and NLR were each determined to be independent factors for birthweight (Table 5).

In the comparison of term and preterm groups, the $\mathrm{Hb}$ value in the preterm group was observed to be

Table 4: Multivariate linear regression analysis to determine independent variables affecting birth week.

\begin{tabular}{|c|c|c|c|c|c|c|c|c|}
\hline \multirow{2}{*}{\multicolumn{2}{|c|}{ Model }} & \multicolumn{2}{|c|}{$\begin{array}{l}\text { Unstandardized } \\
\text { Coefficients }\end{array}$} & \multirow{2}{*}{\begin{tabular}{|l} 
Standardized \\
Coefficients \\
Beta \\
\end{tabular}} & \multirow[t]{2}{*}{$\mathbf{t}$} & \multirow[t]{2}{*}{$p$} & \multicolumn{2}{|c|}{$\begin{array}{c}\text { 95\% Confidence Interval for } \\
\text { B }\end{array}$} \\
\hline & & \multirow{2}{*}{$\begin{array}{l}\text { B } \\
36.78\end{array}$} & \multirow{2}{*}{\begin{tabular}{|l} 
Std. Error \\
0.813 \\
\end{tabular}} & & & & \multirow{2}{*}{\begin{tabular}{|l|} 
Lower Bound \\
35.2
\end{tabular}} & \multirow{2}{*}{\begin{tabular}{|l|} 
Upper Bound \\
38.4
\end{tabular}} \\
\hline 1 & (Constant) & & & & 45.2 & 0.0001 & & \\
\hline & $\mathrm{Hb}$ & 0.11 & 0.063 & 0.073 & 1.8 & 0.026 & 0.034 & 0.281 \\
\hline & $\mathrm{P} / \mathrm{L}$ oranı & -3.06 & 0.000 & -0.085 & -2.2 & 0.031 & 0.000 & 0.000 \\
\hline
\end{tabular}

a. DependentVariable: Birth week

P/L: Platelets to Lymphocyte Ratio

Table 5: Multivariate linear regression analysis to determine independent variables affecting birth weight.

\begin{tabular}{|c|c|c|c|c|c|c|c|c|}
\hline \multirow{2}{*}{\multicolumn{2}{|c|}{ Model }} & \multicolumn{2}{|c|}{$\begin{array}{l}\text { Unstandardized } \\
\text { Coefficients }\end{array}$} & \multirow{2}{*}{\begin{tabular}{|l} 
Standardized \\
Coefficients \\
Beta
\end{tabular}} & \multirow[t]{2}{*}{$\mathbf{t}$} & \multirow[t]{2}{*}{ Sig. } & \multicolumn{2}{|c|}{$\begin{array}{l}95,0 \% \text { Confidence Interval } \\
\text { for B }\end{array}$} \\
\hline & & B & Std. Error & & & & Lower Bound & Upper Bound \\
\hline \multirow[t]{6}{*}{1} & (Constant) & 2630.877 & 333.533 & & 7.888 & 0.000 & 1975.909 & 3285.846 \\
\hline & $\mathrm{Hb}$ & -60.300 & 21.754 & -0.105 & -2.772 & 0.006 & -103.019 & -17.581 \\
\hline & $\mathrm{P} / \mathrm{L}$ ratio & -0.026 & 0.008 & -0.197 & -3.425 & 0.001 & -0.040 & -0.011 \\
\hline & BMI & 50.227 & 5.817 & 0.327 & 8.634 & 0.000 & 38.803 & 61.650 \\
\hline & Neutrophile & -4.158 & 1.739 & -0.137 & -2.390 & 0.017 & -7.573 & -0.742 \\
\hline & $\mathrm{N} / \mathrm{L}$ ratio & 66.542 & 26.074 & 0.192 & 2.552 & 0.011 & 15.340 & 117.744 \\
\hline
\end{tabular}

a. Dependent variable: Birthweight 
statistically significantly lower $(p=0.005)$. Although no statistically significant difference was observed between the groups in respect of the other variables, the WBC, platelet, RDW values and PLR were seen to be higher in the preterm group, and the neutrophil, lymphocyte, PDW and MPV values were observed to be lower. No difference was determined between the groups in respect of the NLR.

In the evaluation of the preterm subgroups, the $\mathrm{Hb}$ value was statistically significantly lowest in the $35^{+0}$ $36^{+6}$ gestational weeks age age group, and the highest value was in the $31^{+0}-32^{+6}$ gestational weeks group $(p=$ 0.005 ). The statistically significantly highest RDW value was observed in the $31^{+0}-32^{+6}$ gestational weeks group $(p=0.001)$. The highest NLR was observed in the $35^{+0}$ $36^{+6}$ gestational weeks group but not at a statistically significant level $(p=0.387)$. The highest PLR value was observed in the $35^{+0}-36^{+6}$ gestational weeks group but not at a statistically significant level ( $p=0.118$ ). No difference was observed between the groups in respect of other $\mathrm{CBC}$ variables.

\section{Discussion}

In this study, it was investigated whether or not there was any relationship between $\mathrm{CBC}$ variables and birthweight, gestational week at birth and preterm severity. A weak negative correlation was determined between PLR and birthweight and gestational week at birth, and NLR was determined to be a weak, positive independent variable for birthweight.

NLR is a simple parameter which easily evaluates the inflammatory status of any event. An increase in NLR measured in the first trimester may be related to various complications of pregnancy associated with underlying inflammatory processes [8-11]. For example, an increase in NLR has been observed in preeclampsia, especially in its severe form. Therefore, NLR is recommended as a marker which can be useful in the first trimester of pregnancy [22]. In a study by Mannaerts, et al. of 164 pre-eclampsia patients and a control group of 1886 subjects, the NLR and MPV value were reported to be higher and the PLR lower in the pre-eclampsia group compared to the control group [9]. Gezer, et al. found neutrophils, platelets, NLR, and PLR to be higher in the pre-eclampsia group [10]. In a study of diabetic pregnant patients, Yilmaz, et al. reported similar results with higher NLR determined [11], and as in the current study, no increase was determined in the NLR in the healthy pregnant patients who had no pregnancy complications. In the current study, the low PLR was concluded to be an independent risk factor for birthweight. Akgun, et al. stated that this showed a relationship between PLR and early births because of prematurity rather than birthweight [22], whereas in the current study, there was seen to be a greater relationship with birthweight according to gestational week at birth rather than prematurity.
There is only one study in literature related to the effect of NLR and PLR on birthweight and the gestational week at birth [22]. In that study, there was concluded to be a relationship between increased NLR and low birthweight. It has been reported in literature that maternal inflammation affects birthweight according to gestational week mediated by various inflammatory cytokines, and leads to low birthweight [25]. In a study by Amarilyo, et al. there were reported to be more inflammatory cytokines in small for gestational age (SGA) infants compared to appropriate for gestational age (AGA) infants [26]. Peiris, et al. analysed the amniotic fluid of women with preterm births and reported an increased concentration of prostoglandins [27]. To the best of our knowledge, the current study is the first to have evaluated whether NLR and PLR have any effect on preterm severity. Although there are many factors affecting prematurity, the population of the current study comprised healthy pregnant patients with no disease, no history of cervical insufficiency and premature birth and thus it was aimed to minimalise additional factors.

Anaemia is one of the most frequently encountered conditions in pregnancy. In a study by Levy, et al. a relationship was shown between maternal anaemia, and preterm birth and IUGR [28]. While the results of the current study support previous findings in literature in respect of the relationship between anaemia and prematurity, there was no evidence of a relationship with IUGR. According to the current study results, the highest $\mathrm{Hb}$ level was obtained in the SGA group, and according to the analysis results, anaemia was not correlated with prematurity severity.

In literature, RDW, PDW and MPV have been associated with both IUGR and prematurity. In a study by Erkenekli et al, increased MPV and RDW values were seen in the IUGR group, and RDW showed a negative correlation with gestational age at birth [29-31]. In the current study, the lowest RDW value was observed in the SGA group. When comparisons were made within the preterm group, the lowest value was statistically significant in the $31^{+0}-32^{+6}$ gestational weeks group $(p=0.001)$. This result suggests that RDW is directly proportional to both gestational week and prematurity severity. In literature, some authors have shown a higher RDW in IUGR and preterm infants [29,31], and some in studies of a neonatal population have reported a negative correlation between RDW and gestational week [32].

While Akgun, et al. determined a higher leukocyte value in male fetal gender [22], in the current study a higher value was seen in female infants, although not at a statistiscally significant level. This contradictory result suggests caution about concluding that there could be a relationship between $\mathrm{CBC}$ variables and fetal gender. 
A limitation of the current study can be said to be that the study group was heterogenous as there were patients of different ethnic origins.

In conclusion, the results of this study showed that there was a negative correlation between NLR and birthweight and gestational week at birth and a negative correlation between PLR and birthweight and gestational week at birth. Although the results showed that low $\mathrm{Hb}$ was associated with early birth, it was not related to low birthweight and the highest $\mathrm{Hb}$ values were observed in low birthweight infants. There is a need for further studies to determine whether maternal $C B C$ variables have any effect on perinatal outcomes, and this easy-to-apply method could be useful in the early determination of perinatal outcomes.

\section{Acknowledgement}

None.

\section{Declarations}

\section{Funding}

None.

\section{Conflicts of interest/Competing interests}

The authors certify that they have NO affiliations with or involvement any organization or entity with any fi nancial interest (such as honoraria; educational grants; participation in speakers' bureaus; membership, employment, consultancies, stock ownership, or other equity interest; and expert testimony or patentlicensing arrangements), or non-fi nancial interest (such as personal or professional relationships, affi liations, knowledge or beliefs) in the subject matter or materials discussed in this manuscript.

\section{Availability of data and material}

Available.

\section{Code availability (software application or custom code)}

None.

\section{Authors' contributions}

Ayca Nazli Bulut: Conception or design of the work, drafting the work, final approval of the version to be published, revising it critically for important intellectual content; Venhar Ceyhan: Interpretation of data for the work, revising it critically for important intellectual content.

\section{Ethics approval}

Approval for the study was granted by the Ethics Committee of Erciyes University. (Ethical approval; Date:29.01.2020. Referance number: 2020/53). All the study procedures were applied in compliance with the Helsinki Declaration.

\section{Informed consent}

Informed consent for participation in the study was obtained from all the participants.

\section{References}

1. Roland MCP, Friis CM, Godang K, Bollerslev J, Haugen G, et al. (2014) Maternal factors associated with fetal growth and birthweight are independent determinants of placental weight and exhibit differential effects by fetal sex. PLoS One 9: 1-5.

2. Naeye RL, Dixon JB (1978) Distortions in fetal growth standards. Pediat Res 12: 987-991.

3. Romero R, Dey SK, Fisher SJ (2014) Preterm labor: One syndrome, many causes. Science 34: 760-766.

4. Mayer C, Joseph KS (2013) Fetal growth: A review of terms, concepts and issues relevant to obstetrics. Ultrasound Obstet Gynecol 41: 136-145.

5. Ichipi-Ifukor PC, Jacobs J, Ichipi-Ifukor RN, Ewrhe OL (2013) Changes in haematological indices in normal pregnancy. Physiology Journal.

6. Yip R (2000) Significance of an abnormally low or high hemoglobin concentration during pregnancy: Special consideration of iron nutrition. The American Journal of Clinical Nutrition 72: 272-279.

7. Chandra S, Tripathi AK, Mishra S, Amzarul M, Vaish AK (2012) Physiological changes in hematological parameters during pregnancy. Indian J Hematol Blood Transfus 28: 144-146.

8. Gezer C, Ekin A, Ertas IE, Ozeren M, Solmaz U, et al. (2016) High first-trimester neutrophil-to-lymphocyte and plateletto-lymphocyte ratios are indicators for early diagnosis of preeclampsia. Ginekologia Polska 87: 431-435.

9. Yilmaz H, Celik HT, Namuslu M, Inan O, Onaran $Y$, et al. (2014) Benefits of the neutrophil-to lymphocyte ratio for the prediction of gestational diabetes mellitus in pregnant women. Exp Clin Endocrinol Diabetes 122: 39-43.

10. Caglayan EK, Engin-Ustun Y, Gocmen AY, Sarı N, Seckin L, et al. (2016) Is there any relationship between serum sirtuin-1 level and neutrophil-lymphocyte ratio in. Hyperemesis gravidarum? J Perinat Med 44: 315-320.

11. Kim MA, Lee YS, Seo K (2014) Assessment of predictive markers for placental inflammatory response in preterm births. PLoS One 9: e107880.

12. Huang QT, Zhou L, Zeng WJ, Ma Q, Wang W, et al. (2017) Prognostic significance of neutrophil-to-lymphocyte ratio in ovarian cancer: A systematic review and meta-analysis of observational studies. Cell Physiol Biochem 41: 2411-2418.

13. Akinci Ozyurek B, Sahin Ozdemirel T, Buyukyaylaci Ozden S, Erdogan Y, Kaplan B, et al. (2017) Prognostic value of the neutrophil to lymphocyte ratio (NLR) in lung cancer cases. Asian Pac J Cancer Prev 18: 1417-1421.

14. Iwase T, Sangai T, Sakakibara M, Sakakibara J, Ishigami E, et al. (2017) An increased neutrophil-to-lymphocyte ratio predicts poorer survival following recurrence for patients with breast cancer. Mol Clin Oncol 6: 266-270.

15. Piciucchi M, Stigliano S, Archibugi L, Zerboni G, Signoretti M, et al. (2017) The neutrophil/lymphocyte ratio at diagnosis is significantly associated with survival in metastatic pancreatic cancer patients. Int J Mol Sci 18: 730.

16. Tang X, Du P, Yang Y (2017) The clinical use of neutrophil- 
to-lymphocyte ratio in bladder cancer patients: a systematic review and meta-analysis. Int J Clin Oncol 22: 817-825.

17. Brooks SD, Spears C, Cummings C, VanGilder RL, Stinehart $\mathrm{KR}$, et al. (2014) Admission neutrophil-lymphocyte ratio predicts 90 day outcome after endovascular stroke therapy. J Neurointerv Surg 6: 578-583.

18. Lattanzi S, Cagnetti C, Rinaldi C, Angelocola S, Provinciali L, et al. (2018) Neutrophil-to-lymphocyte ratio improves outcome prediction of acute intracerebral hemorrhage. J Neurol Sci 387: 98-102.

19. Hwang SY, Shin TG, Jo IJ, Jeon K, Suh GY, et al. (2017) Neutrophilto- lymphocyte ratio as a prognostic marker in critically-ill septic patients. Am J Emerg Med 35: 234-239.

20. Surendar J, Indulekha K, Mohan V, Pradeepa R (2016) Association of neutrophil- lymphocyte ratio with metabolic syndrome and its components in Asian Indians (CURES-143). J Diabetes Complications 30: 1525-1529.

21. Kirbas A, Biberoglu E, Daglar K, Iskender C, Erkaya S, et al. (2014) Neutrophil-to-lymphocyte ratio as a diagnostic marker of intrahepatic cholestasis of pregnancy. Eur $J$ Obstet Gynecol Reprod Biol 180: 12-15.

22. Akgun N, Kalem MN, Yuce E, Kalem Z, Aktas H (2019) Correlations of maternal neutrophil to lymphocyte ratio (NLR) and platelet to lymphocyte ratio (PLR) with birth weight. J Matern Fetal Neonatal Med 30: 2086-2091.

23. Chauhan SP, Gupta LM, Hendrix NW, Berghella V (2009) Intrauterine growth restriction: Comparison of american college of obstetricians and gynecologists practice bulletin with other national guidelines. Am J Obstet Gynecol 409: 1-6.

24. (2000) ACOG Practice bulletin No.22: Fetal macrosomia. American College of Obstetricians and Gynecologist, Washington DC.
25. Kurtoglu E, Kokcu A, Celik H, Migraci Tosun M, Malatyalioglu E (2014) May ratio of neutrophil to lymphocyte be useful in predicting the risk of developing preeclampsia? A pilot study. J Matern Fetal Neonatal Med 28: 97-99.

26. Amarilyo G, Oren A, Mimouni FB, Ochshorn Y, Deutsch V, et al. (2011) Increased cord serum inflammatory markers in small-for-gestational-age neonates. J Perinatol 31: 30-32.

27. Erkenekli K, Oztas E, Ozler S, Yucel A, Uygur D, et al. (2015) Complete blood count indices in pregnancies with isolated intrauterine growth restriction. The Journal of Gynecology - Obstetrics and Neonatology 12: 18-21.

28. Levy A, Fraser D, Katz M, Mazor M, Sheiner E (2005) Maternal anemia during pregnancy is an independent risk factor for low birthweight and preterm delivery. Eur J Obstet Gynecol Reprod Biol 122: 182-186.

29. Garofoli F, Ciardelli L, Mazzucchelli I, Borghesi A, Angelini $\mathrm{M}$, et al. (2014) The red cell distribution width (RDW): Value and role in preterm, IUGR (intrauterine growth restricted), full-term infants. Hematology 19: 365-370.

30. Ulkumen BA, Pala HG, Calik E, Koltan So (2014) Platelet distribution width (PDW): A putative marker for threatened preterm labour. Pak J Med Sci 30: 745-748.

31. Farhan FS (2016) Mean platelet volume and platelet distribution width as predictors for preterm labour. Iraqi Medical Journal 62: 95-99.

32. Shehata HA, Ali MM, Evans-Jones JC, Upton GJG, Manyonda IT (1998) Red cell distribution width _RDW changes in pregnancy. International Journal of Gynecology \& Obstetrics 62: 43-46. 